\title{
Recurrence of mitral regurgitation after partial versus complete mitral valve ring annuloplasty for functional mitral regurgitation
}

\author{
Michael H. Kwon, MD, Lawrence S. Lee, MD, Marisa Cevasco, MD, MPH, Gregory S. Couper, MD, \\ Prem S. Shekar, MD, Lawrence H. Cohn, MD, and Frederick Y. Chen, MD, PhD
}

\begin{abstract}
Objectives: Both partial and complete annuloplasty rings are used for mitral valve repair for patients with functional mitral regurgitation (FMR). We sought to determine if recurrence of mitral regurgitation (MR) is affected by the type of ring used.
\end{abstract}

\begin{abstract}
Methods: Five hundred forty-eight patients diagnosed with FMR underwent mitral valve repair with ring annuloplasty between 1998 and 2008 in our institution. Medical records were reviewed retrospectively for clinical and echocardiographic data to determine the presence of recurrent MR (defined as moderate or severe).
\end{abstract}

\begin{abstract}
Results: Among 479 patients for whom postoperative echocardiographic data were available, recurrent MR occurred less frequently in the complete versus partial ring group (20 of 209 [10\%] vs 56 of 270 [21\%] patients; $P=.001$ ), despite lower preoperative ejection fractions in the complete ring group (median, $35 \%$; interquartile range, $25 \%-45 \%$ vs median, $40 \%$; interquartile range, $30 \%-55 \% ; P<.001$ ). Kaplan-Meier analysis demonstrated greater freedom from recurrent MR in the complete ring group (108 vs 103 months; $P=.001)$. Riskmatched propensity analysis of 102 patients per group (area under the curve, $0.824 ; 95 \%$ confidence interval, $0.788-0.861 ; P<.001)$ also demonstrated that complete ring recipients had greater freedom from recurrent MR than partial ring recipients by univariate analysis (7 [7\%] vs $17[17 \%]$ patients; $P=.049)$, and a trend toward greater freedom by Kaplan-Meier analysis (110 vs 104 months; $P=.068$ ).
\end{abstract}

Conclusions: The use of complete mitral annuloplasty rings provides improved freedom from recurrent MR in patients with FMR. (J Thorac Cardiovasc Surg 2013;146:616-22)

Functional mitral regurgitation (FMR) is a type of mitral regurgitation (MR) that occurs despite structurally normal mitral valve leaflets, usually in patients with advanced ischemic or idiopathic dilated cardiomyopathy. ${ }^{1,2}$ FMR carries a poor prognosis with medical treatment alone, resulting in 1-year survival rates of $52 \%$ to $87 \%$ and 5 -year survival rates of $22 \%$ to $54 \%$. $^{3-6}$

The pathophysiology of FMR is complex. As dilated cardiomyopathy worsens, ongoing left ventricular remodeling and dilation are associated with subtle structural changes to the mitral valve apparatus, including mitral annular dilation, lateral displacement of the posteromedial papillary muscle, and tethering of the mitral valve leaflets. Together, these changes prevent proper coaptation of the mitral valve leaflets during systole, ultimately resulting in retrograde flow across the valve. The annular

From the Division of Cardiac Surgery, Brigham and Women's Hospital, Harvard Medical School, Boston, Mass.

This study was supported by the J. Paul Finnegan Endowment in Cardiac Surgery Research.

Disclosures: Authors have nothing to disclose with regard to commercial support. Received for publication April 17, 2012; revisions received July 16, 2012; accepted for publication July 26, 2012; available ahead of print Aug 27, 2012.

Address for reprints: Frederick Y. Chen, MD, PhD, Division of Cardiac Surgery, Brigham and Women's Hospital, 75 Francis St, Boston, MA 02115 (E-mail: fchen@ partners.org).

0022-5223/\$36.00

Copyright (C) 2013 by The American Association for Thoracic Surgery

http://dx.doi.org/10.1016/j.jtcvs.2012.07.049 dilation component of these structural changes has been the most widely recognized aspect of the pathophysiology of FMR. As such, the intent of mitral ring annuloplasty in this setting is to reduce the size of the annulus so that proper coaptation of the leaflets is restored, thereby eliminating regurgitation. This approach is effective in the acute correction of FMR in a majority of patients, and has therefore been the primary surgical method of treating FMR clinically. Unfortunately, it has been associated with rates of recurrent MR as high as $15 \%$ to $30 \%{ }^{7-9}$

Currently, both partial (C-ring) and complete (O-ring) annuloplasty rings are used for mitral annuloplasty in patients with FMR. Prior reports have not demonstrated any difference in durability of repair between the $2 .{ }^{10,11}$ Accordingly, there are no clear principles that guide the choice of 1 type of ring over another in the clinical practice of most surgeons other than anecdotal information about the superiority of 1 type of ring over the other. A recent retrospective study ${ }^{12}$ showed that for patients with degenerative MR, the use of complete, semirigid annuloplasty rings was associated with lower rates of recurrent MR compared with partial flexible annuloplasty rings. To date, this has not been investigated specifically in patients with FMR, in whom both the pathophysiology of the MR itself and the operative approach are significantly different. We therefore sought to 


\section{Abbreviations and Acronyms \\ FMR = functional mitral regurgitation \\ LV EDD = Left ventricular end-diastolic \\ index dimension index \\ MR = mitral regurgitation \\ SAM $=$ systolic anterior motion}

determine if the rate of recurrence of MR in patients with FMR was affected by the type of ring used.

\section{METHODS \\ Study Design}

This study is a retrospective, nonrandomized review of all patients who underwent mitral valve repair using undersized mitral ring annuloplasty as the primary intervention for FMR between 1998 and 2008 at our institution. The study was approved by the internal Institutional Review Board with a waiver for patient consent.

\section{Patients}

A total of 548 patients between October 1998 and December 2008 who underwent mitral valve repair using mitral ring annuloplasty without the use of edge-to-edge Alfieri stitch repair for the diagnosis of FMR were identified in the Society of Thoracic Surgeons database (version 2.52). FMR was defined as the presence of all 3 of the following criteria: a documented diagnosis of ischemic or idiopathic dilated cardiomyopathy; MR by echocardiography not attributable by echocardiographic criteria to degenerative disease; and intraoperative findings from the operative report describing the presence of normal, nondegenerative mitral valve leaflets.

Preoperative clinical data collected include the patient's age, sex, height, weight, calculated body surface area, preoperative New York Heart Association Functional Class, ejection fraction and degree of MR by preoperative echocardiogram, presence of preoperative atrial fibrillation, diabetes mellitus, hypertension, chronic lung disease, chronic renal failure, hyperlipidemia, stroke, peripheral vascular disease, preoperative intraaortic balloon pump requirement, and the etiology of FMR (ischemic or idiopathic). Left ventricular end-diastolic dimension index (LV EDD Index) was calculated by dividing the measured LV EDD by the calculated patient body surface area.

The primary end point was the incidence of recurrent MR, defined by the presence of moderate-to-severe MR by echocardiography at any postoperative time point within the study period. The final cohort of patients was ultimately composed of 479 total patients for whom postoperative echocardiographic data were available. Among these patients, 270 received partial rings and 209 received complete rings.

\section{Surgical Management}

All patients underwent mitral valve procedures, with or without concomitant heart procedures, performed by 1 of 13 surgeons. Intraoperative echocardiography was performed in all patients before and immediately following mitral valve annuloplasty ring placement. Exposure was provided by median sternotomy for most patients, except for 38 patients $(8 \%)$ in whom either minimally invasive thoracotomy or hemisternotomy was performed. All procedures were performed with the use of mild systemic hypothermic cardiopulmonary bypass with intermittent crystalloid cardioplegia to provide myocardial protection. Exposure to the mitral apparatus was achieved through a traditional left atrial incision along Sondergaard's groove. Patients received one of three types of partial rings or 1 of 5 types of complete rings. The choice of ring was left to the discretion of the surgeon at the time of operation. Of note, the Carbomedics Annuloflex ring (Sulzer Carbomedics, Inc, Austin, Tex (division of Sulzer Medica) has the capability of being implanted in partial or complete configuration and is therefore represented in both groups. Rings were downsized in standard fashion by choosing a ring 1 or 2 sizes smaller than predicted by measuring the height of the anterior leaflet.

\section{Follow-up}

Postoperative echocardiographic and clinical data, including postoperative complications and mortality were obtained from the Society of Thoracic Surgeons and departmental databases, institutional electronic medical records, and query of the Social Security Death Index. The primary end point for this study was the postoperative recurrence of MR, defined in this study as either $3+$ (moderate) or $4+$ (severe) MR at any time point during the study period. 30-day mortality was defined as mortality within 30 days regardless of hospital discharge, whereas operative mortality was defined according to the Society of Thoracic Surgeons definition (ie, mortality within 30 days and/or death before discharge from the index hospitalization).

\section{Statistical Analysis}

Categorical data are expressed as numbers and percentage, and continuous data as means \pm standard deviation or medians and interquartile range for normally or non-normally distributed data. Categorical variables were compared using the Fisher exact test. Continuous variables were compared using the Student $t$ test with the Levine test for homogeneity of variance or Mann-Whitney U test as appropriate.

A risk-matched propensity analysis consisted of a logistic regression analysis. Based on available literature, clinical expertise, patient characteristics, and known operative differences, we selected factors contributing to the likelihood of receiving a complete or partial ring. These were entered into a multivariable forward stepwise logistic regression. Interactions were examined, and the interaction variable between the surgeon and year of surgery was included to control for differences in the patient comorbidity loads and techniques over time. Any variable significant at a $P$ value $\leq .15$ was retained. The resulting adjusted predicted value for each patient was calculated, and a 1:1 complete:partial ring match based on predicted value (nearest thousandth place) was derived. Subsequent analyses were performed on this cohort of 204 subjects ( $n=102$ per group).

Enter-method Cox regression analysis of the unmatched cohort was performed to evaluate if ring type was an independent variable for MR recurrence. Covariates with known associations with greater severity of disease and for which complete data were available were included for analysis.

Survival was estimated by using Kaplan-Meier analyses. Statistical analyses were performed with SPSS version 13.0 (2005; IBM, Armonk, NY).

\section{RESULTS \\ Overall Results}

We limited the majority of our analyses to the 479 of 548 subjects with follow-up echocardiographic data available. A responder bias analysis between these subjects and the 69 for whom we lacked postoperative echocardiographic data showed no significant differences with respect to age, sex, preoperative cardiac measures, operative times, or concomitant procedures (data not shown).

Among 479 patients for whom postoperative echocardiographic data were available, Table 1 shows that complete ring recipients had significantly lower preoperative ejection fractions and a higher proportion of patients requiring preoperative intra-aortic balloon pump support compared with partial ring recipients, but were similar with regard to all other 
TABLE 1. Patient characteristics

\begin{tabular}{|c|c|c|c|}
\hline Characteristic & $\frac{\text { Partial }}{(n=270)}$ & $\frac{\text { Complete }}{(n=209)}$ & $P$ value \\
\hline Age $($ mean $y \pm S D)$ & $69.3 \pm 10.6$ & $67.9 \pm 10.2$ & $\leq .13$ \\
\hline Females & $135(50)$ & $88(42)$ & $\leq .1$ \\
\hline $\begin{array}{l}\text { Body surface area } \\
\quad\left(\text { mean } \mathrm{m}^{2} \pm \mathrm{SD}\right)\end{array}$ & $1.88 \pm 0.24$ & $1.90 \pm 0.26$ & $\leq .48$ \\
\hline Mitral regurgitation grade & & & $\leq .85$ \\
\hline 2 & $1(0.4)$ & $0(0)$ & \\
\hline 3 & $130(48)$ & $104(50)$ & \\
\hline 4 & $139(51)$ & $105(50)$ & \\
\hline NYHA Functional Class & & & $\leq .34$ \\
\hline I & $31(11)$ & $24(11)$ & \\
\hline II & $88(33)$ & $56(27)$ & \\
\hline III & $120(44)$ & $96(46)$ & \\
\hline IV & $30(11)$ & $33(16)$ & \\
\hline Etiology of FMR & & & $\leq .45$ \\
\hline Ischemic & $165(61)$ & $135(65)$ & \\
\hline Idiopathic & $105(39)$ & $74(35)$ & \\
\hline $\begin{array}{l}\text { Ejection fraction } \\
\quad(\text { median \% } \%[\mathrm{QQR}])\end{array}$ & $40(30-55)$ & $35(25-45)$ & $\leq .001^{*}$ \\
\hline $\begin{array}{l}\text { LV EDD }=\text { Index } \\
\quad\left(\text { mean } \mathrm{cm} / \mathrm{m}^{2} \pm \mathrm{SD}\right)\end{array}$ & $3.1 \pm 0.7$ & $3.2 \pm 0.6$ & $\leq .65$ \\
\hline IABP support & $14(5)$ & $24(11)$ & $\leq .02 *$ \\
\hline Atrial fibrillation & $78(29)$ & $52(25)$ & $\leq .35$ \\
\hline Diabetes mellitus & $76(28)$ & $62(30)$ & $\leq .76$ \\
\hline Hypertension & $187(70)$ & $148(71)$ & $\leq .76$ \\
\hline Chronic lung disease & $49(18)$ & $42(20)$ & $\leq .64$ \\
\hline Chronic renal failure & $34(13)$ & $36(17)$ & $\leq .19$ \\
\hline Hyperlipidemia & $165(61)$ & $138(66)$ & $\leq .29$ \\
\hline Stroke & $21(8)$ & $19(9)$ & $\leq .92$ \\
\hline Peripheral vascular disease & $45(17)$ & $25(12)$ & $\leq .15$ \\
\hline
\end{tabular}

Continuous data are presented as mean \pm standard deviation (SD) for normally distributed data and as median and interquartile range for non-normally distributed data as indicated above. Categorical data are presented as the number of patients (\%) in each category. NYHA, New York Heart Association; FMR, functional mitral regurgitation; $L V E D D$ Index, left ventricular end-diastolic diameter index (LV EDD normalized to body surface area); $I A B P$, Intra-aortic balloon pump (preoperative); IQR, interquartile range. *Statistically significant.

preoperative risk factors including severity of MR, LV EDD Index, and ring size (which was in accordance with median ring sizes observed in similar studies of annuloplasty for $\mathrm{FMR}^{7}$ ).

Intraoperatively, complete rings were associated with significantly longer perfusion times (median 180 vs 139 minutes for partial rings; $P<.001)$ and cross-clamp times (median 120 vs 97 minutes; $P<.001$ ). Subjects receiving complete rings were significantly more likely to have concomitant tricuspid valve procedures, which may partly contribute to the longer operative times (Table 2). The percentage of patients receiving complete rings by year beginning in 1998 was $0 \%, 50 \%, 67 \%, 58 \%, 32 \%, 21 \%, 24 \%$, $34 \%, 57 \%, 71 \%$, and $82 \%$.

Postoperatively, for the primary end point, recurrent MR occurred more frequently in patients who received partial rings compared with those who received complete rings (56 of 270 patients [21\%] vs 20 of 209 patients [10\%];
TABLE 2. Operative data

\begin{tabular}{|c|c|c|c|}
\hline Characteristic & $\frac{\text { Partial }}{(n=270)}$ & $\frac{\text { Complete }}{(n=209)}$ & $P$ value \\
\hline Minimally invasive & $26(10)$ & $12(6)$ & $\leq .13$ \\
\hline $\mathrm{CPB}($ mean $\min \pm \mathrm{SD})$ & $148 \pm 63$ & $188 \pm 69$ & $\leq .001 *$ \\
\hline Cross-clamp (mean $\min \pm \mathrm{SD})$ & $105 \pm 50$ & $129 \pm 52$ & $\leq .001 *$ \\
\hline \multicolumn{4}{|l|}{ Concomitant procedures } \\
\hline CABG & $160(59)$ & $126(60)$ & $\leq .85$ \\
\hline Aortic valve & $55(20)$ & $29(14)$ & $\leq .07$ \\
\hline Tricuspid valve & $47(17)$ & $64(31)$ & $\leq .001 *$ \\
\hline Pulmonic valve & $1(0.4)$ & $2(1)$ & $\leq .58$ \\
\hline \multicolumn{4}{|l|}{ Mitral procedures } \\
\hline Commissuroplasty & $1(0.4)$ & $5(2)$ & $\leq .09$ \\
\hline Cleft repair (anterior leaflet) & $1(0.4)$ & $0(0)$ & $\leq 1$ \\
\hline Cleft repair (posterior leaflet) & $5(2)$ & $3(1)$ & $\leq 1$ \\
\hline Anterior chordal release & $1(0.4)$ & $1(0.5)$ & $\leq 1$ \\
\hline Posterior leaflet resection & $0(0)$ & $1(0.5)$ & $\leq .44$ \\
\hline \multicolumn{4}{|l|}{ Ring type } \\
\hline Carbomedics Annuloflex $\dagger$ & $66(24)$ & $69(33)$ & N/A \\
\hline C-G Future Band $\ddagger$ & $6(2.2)$ & $0(0)$ & N/A \\
\hline Cosgrove-Edwards $\S$ & $198(73)$ & $0(0)$ & N/A \\
\hline Carpentier-Edwards Physio $§$ & $0(0)$ & $96(46)$ & N/A \\
\hline Geoform $\S$ & $0(0)$ & $31(15)$ & N/A \\
\hline Carbomedics Memo 3D $\dagger$ & $0(0)$ & $8(4)$ & N/A \\
\hline St Jude Saddle $\|$ & $0(0)$ & $5(2)$ & N/A \\
\hline Ring size (mean $\mathrm{mm} \pm \mathrm{SD}$ ) & $28.6 \pm 2.3$ & $28.4 \pm 2.3$ & $\leq .24$ \\
\hline
\end{tabular}

Continuous data are presented as mean \pm standard deviation (SD) as indicated above. All categorical data are presented as numbers of patients (\%) in each. $C P B$, Cardiopulmonary bypass; $C$ - $G$ Future Band, Colvin-Galloway Future Band; N/A, not applicable; $C A B G$, coronary artery bypass graft. *Statistically significant. †Sorin Group, Milan, Italy. $\ddagger$ Medtronic Inc, Minneapolis, Minn. §Edwards Lifesciences, Irvine, Calif. ||St Jude Medical, Inc, St Paul, Minn.

$P=.001)$. The proportion of patients with recurrence occurring within the first 6 months postoperatively was similar between groups (19 of 56 partial ring recipients [34\%], 6 of 20 complete ring recipients [30\%]; $P=1.0]$. There was a strong trend towards a higher mean time to echocardiographic follow-up in the partial compared with the complete ring group (17.7 \pm 25.0 vs $13.5 \pm 20.0$ months; $P=.06)$. Median freedom from recurrent MR was longer in complete ring recipients compared with partial ring recipients by survival estimation (108 vs 103 months; $P=.001$ based on Kaplan-Meier analysis (Figure 1, A). However, there was no difference in survival between the two groups with a median survival of 101 months in the partial ring group and 103 months in the complete ring group $(P=.85$ based on Kaplan-Meier analysis) (Figure 1, $B$ ).

Because echocardiographic data were missing from $12 \%$ of the initial cohort of 548 patients, we performed KaplanMeier analysis of freedom from recurrent MR considering the study end point as indeterminate for the recurrence of $\mathrm{MR}$ and found that complete ring group retained its longer period of freedom from MR compared with the partial ring group (134 vs 110 months; $P=.008$ ) (data not shown).

There were no major differences in the major categories of postoperative complications between the partial ring group 

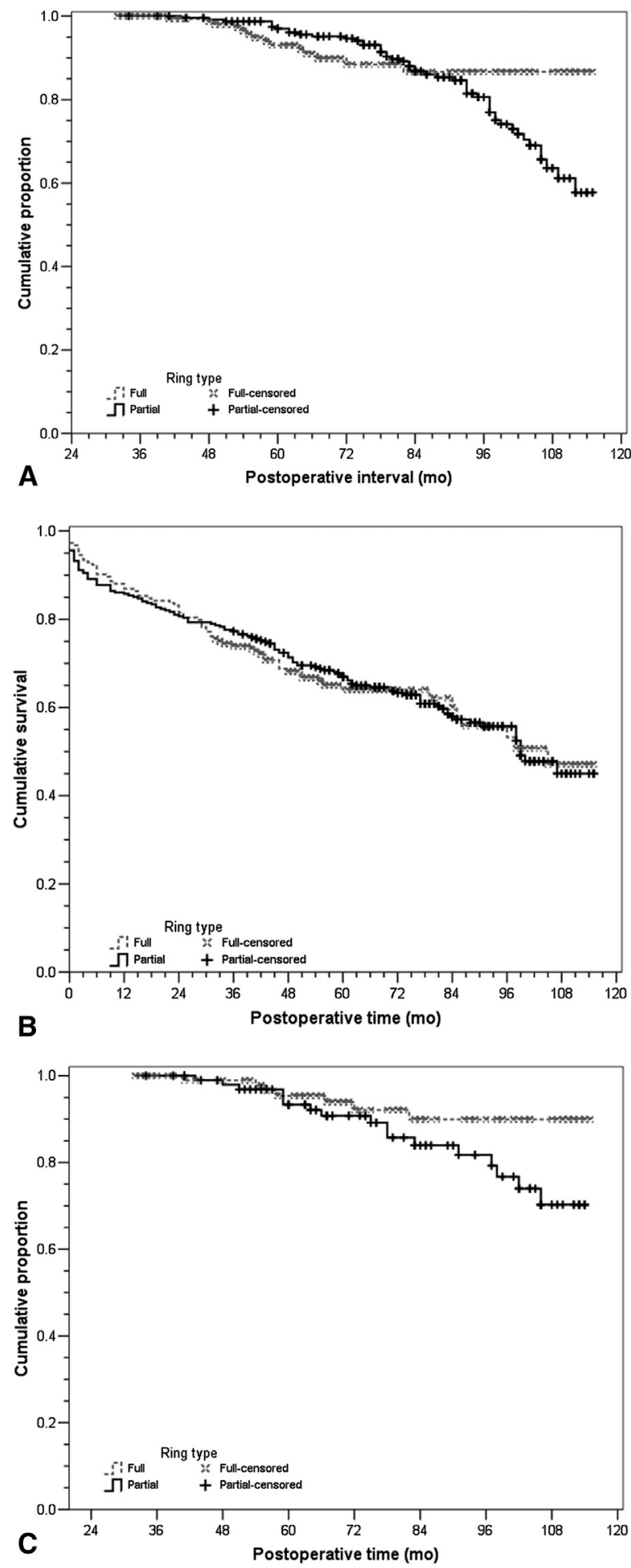

FIGURE 1. Kaplan-Meier analysis: Freedom from recurrent mitral regurgitation (MR) and survival. A, Freedom from recurrent MR in unmatched cohorts. There were 270 subjects in the partial ring group (black line); and 209 subjects in the complete ring group (gray dash). B, Survival curves in unmatched cohorts. There were 270 in the partial ring group (black line); and 209 subjects in the complete ring group (gray dash). C, Freedom from recurrent MR in risk-matched cohorts ( $\mathrm{n}=102$ patients per group). Partial ring group (black line); complete ring group (gray dash). versus the complete ring group by univariate analysis, including 30-day mortality $(1.0 \%$ vs $1.4 \% ; P=.55)$, operative mortality $(4.4 \%$ vs $2.4 \% ; P=.32)$, new onset postoperative atrial fibrillation $(22 \%$ vs $25 \% ; P=.45)$, multisystem organ failure $(0.7 \%$ vs $1 \% ; P=1.0)$, gastrointestinal complications $(63 \%$ vs $4.3 \% ; P=.42)$, cardiac arrest $(2.6 \%$ vs $2.4 \% ; P=1.0)$, acute renal failure $(7.4 \%$ vs $8.1 \%$; $P=.86)$, pneumonia $(4.1 \%$ vs $2.9 \% ; P=.62)$, pulmonary embolism $(0.4 \%$ vs $0 \% ; P=1.0)$, stroke $(4.1 \%$ vs $4.8 \%$; $P=.89)$, and sepsis $(4.1 \%$ vs $2.4 \% ; P=.44)$. There was no difference in the mean change in ejection fraction $(2 \%$ $\pm 14 \%$ in the complete ring group and $2 \% \pm 13 \%$ in the partial ring group; $P=.94$ ).

\section{Risk-Matched Propensity Analyses}

Using the methods described above, we developed a moderately robust model to test the hypothesis that the type of ring can predict the rate of MR recurrence (area under the curve, $0.824 ; 95 \%$ confidence interval $[\mathrm{CI}], 0.788$ $0.861 ; P<.001)$. We were able to match 102 complete ring subjects per cohort (complete vs partial rings).

Table 3 shows the characteristics and outcomes of the matched cohort. Although the groups were substantially similar, the trend toward longer cross-clamp and perfusion times in the complete ring group remained, but it was not statistically significant. On the primary end point, patients in the partial ring group had a significantly higher risk of developing recurrent MR during the study period (17 [17\%] vs 7 [7\%] patients; odds ratio [OR], 2.714; 95\% CI, 1.074-6.863; $P=.049$ ). Kaplan-Meier analysis of freedom from recurrent MR showed a trend toward improved freedom from recurrent MR in the complete ring group (110 vs 104 months; $P=.068)$ (Figure 1,C).

\section{Cox Regression Analysis}

Among the covariates tested, the strongest predictors for MR recurrence were the use of partial rings (OR, 2.001; 95\% CI, 1.164-3.441; $P=.012$ ), preoperative MR grade 4 (OR, 2.081; 95\% CI, 1.243-3.485; $P=.005)$, and previous valve procedures (OR, 1.031; 95\% CI, 0.970-1.761; $P=.063)$. All other tested variables were nonsignificant, including age $(P=.844)$, being a woman $(P=.968)$, preoperative ejection fraction $(P=.687)$, New York Heart Association Functional Class IV $(P=.275)$, concomitant coronary artery bypass graft surgery $(P=.703)$, and cardiopulmonary bypass time $(P=.230)$.

\section{DISCUSSION}

\section{Recurrence of MR}

The major conclusion of this retrospective review comparing the use of partial to complete ring mitral annuloplasty for patients with FMR is that despite evidence to suggest that patients receiving complete rings had greater 
TABLE 3. Characteristics and postoperative outcomes for riskmatched propensity group analysis

\begin{tabular}{|c|c|c|c|}
\hline & Partial & Complete & \\
\hline Characteristic & $(n=102)$ & $(\mathbf{n}=102)$ & $P$ valu \\
\hline \multicolumn{4}{|l|}{ Preoperative } \\
\hline Age (mean y \pm SD) & $68.6 \pm 11.0$ & $68.4 \pm 10.2$ & .87 \\
\hline Women & $53(52)$ & $41(40)$ & .12 \\
\hline $\begin{array}{l}\text { Body surface area } \\
\qquad\left(\text { mean } \mathrm{m}^{2} \pm \mathrm{SD}\right)\end{array}$ & $1.9 \pm 0.2$ & $1.9 \pm 0.2$ & .23 \\
\hline Diabetes mellitus & $26(26)$ & $31(30)$ & .53 \\
\hline Chronic renal failure & $14(14)$ & $16(16)$ & .84 \\
\hline $\begin{array}{l}\text { Preoperative creatinine } \\
\quad(\text { mean } \pm \mathrm{SD})\end{array}$ & $1.4 \pm 0.9$ & $1.3 \pm 0.6$ & .38 \\
\hline Hypercholesterolemia & $70(69)$ & $70(69)$ & 1.0 \\
\hline Stroke & $8(8)$ & $10(10)$ & .81 \\
\hline Peripheral vascular disease & $15(15)$ & $12(12)$ & .68 \\
\hline Atrial fibrillation & $27(27)$ & $25(25)$ & .87 \\
\hline Myocardial infarction & $45(44)$ & $44(43)$ & 1.0 \\
\hline \multicolumn{4}{|l|}{ NYHA Functional Class } \\
\hline I & $11(11)$ & $12(12)$ & 1.0 \\
\hline II & $33(32)$ & $30(29)$ & .76 \\
\hline III & $45(44)$ & $45(44)$ & 1.0 \\
\hline IV & $13(13)$ & $15(15)$ & .84 \\
\hline \multicolumn{4}{|l|}{ Etiology of FMR } \\
\hline Ischemic & $66(65)$ & $63(62)$ & .77 \\
\hline Idiopathic & $36(35)$ & $39(38)$ & .77 \\
\hline $\begin{array}{l}\text { Ejection fraction } \\
\quad(\text { median } \%[\mathrm{IQR}])\end{array}$ & $35(25-50)$ & $35(25-50)$ & .79 \\
\hline \multicolumn{4}{|l|}{ Intraoperative } \\
\hline Emergent procedure & $6(6)$ & $3(3)$ & .50 \\
\hline IABP support & $20(20)$ & $19(19)$ & 1.0 \\
\hline \multicolumn{4}{|l|}{ Concomitant procedures } \\
\hline CABG & $62(61)$ & $63(62)$ & 1.0 \\
\hline Aortic valve & $19(19)$ & $17(17)$ & .86 \\
\hline Tricuspid valve & $25(25)$ & $22(22)$ & .74 \\
\hline $\mathrm{CPB}($ median min $[\mathrm{IQR}])$ & $153(111-207)$ & $173(132-218)$ & .12 \\
\hline $\begin{array}{l}\text { Cross-clamp (median } \\
\text { min [IQR]) }\end{array}$ & $100(68-137)$ & $119(75-160)$ & .083 \\
\hline \multicolumn{4}{|l|}{ Postoperative } \\
\hline Reoperation for bleed & $1(1)$ & $4(4)$ & .62 \\
\hline Permanent stroke & $6(6)$ & $3(3)$ & .50 \\
\hline Pulmonary embolism & $1(1)$ & $0(0)$ & 1.0 \\
\hline New onset renal failure & $10(10)$ & $11(11)$ & 1.0 \\
\hline Coagulopathy & $8(8)$ & $4(4)$ & .54 \\
\hline New onset atrial fibrillation & $47(46)$ & $42(41)$ & .57 \\
\hline Operative mortality* & $8(8)$ & $4(4)$ & .54 \\
\hline $\begin{array}{l}\text { Length of stay } \\
\quad \text { (median d [IQR]) }\end{array}$ & $10(7-18)$ & $10(8-15)$ & .91 \\
\hline $\begin{array}{l}\text { Ejection fraction } \\
\quad(\text { median \% [IQR]) }\end{array}$ & $40(30-55)$ & $40(30-50)$ & .25 \\
\hline Recurrence of MR $(3+$ or $4+)$ & $17(17)$ & $7(7)$ & .049 \\
\hline
\end{tabular}

Categorical data are presented as the number of patients (\%) in each. Non-normally distributed continuous data are presented as the median (IQR). Normally distributed continuous data are presented as means $\pm \mathrm{SD}$. $S D$, Standard deviation; NYHA, New York Heart Association; FMR, functional mitral regurgitation; $I Q R$, interquartile range; $I A B P$, intra-aortic balloon pump; $C A B G$, coronary artery bypass graft; $C P B$, cardiopulmonary bypass; $A F$, atrial fibrillation; $M R$, mitral regurgitation. *Based on The Society of Thoracic Surgeons definition: 30-day mortality plus mortality before hospital discharge. risk factors for ongoing deterioration of cardiac function (as evidenced by lower left ventricular ejection fraction, greater prevalence of preoperative intra-aortic balloon pump support, more frequent need for concomitant tricuspid valve procedures, and longer bypass and cross-clamp times), the use of complete mitral annuloplasty rings was associated with greater freedom from the onset of recurrent moderate to severe MR than the use of partial rings. This relationship was demonstrated in unmatched cohorts by univariate analysis demonstrating roughly a twofold greater risk of recurrent MR in complete ring recipients, with the caveat that the partial ring group had a trend toward longer mean time to postoperative echocardiographic follow-up than the complete ring group, which may present followup bias in favor of improved freedom from recurrent MR in the complete ring group. To overcome this limitation of our study, we performed Kaplan-Meier analysis of the unmatched cohort, univariate analysis of the propensitymatched groups, and Cox regression multivariate analysis of the unmatched cohort; all 3 analyses demonstrated significantly higher risk of MR recurrence in patients receiving partial rings compared with complete rings. In addition, Kaplan-Meier analysis of the risk-matched groups showed a strong trend toward longer freedom from recurrent MR in the complete ring group.

The most well-accepted preoperative factors that specifically predict a higher rate of recurrence of MR after annuloplasty include increased preoperative left ventricle dilation with LV EDD $>65 \mathrm{~mm},{ }^{13}$ higher severity of preoperative $\mathrm{MR}^{7,14}$ and lower preoperative left ventricular ejection fraction. ${ }^{7,14}$ In both unmatched and matched cohort analyses in our study, these 3 factors were either equivalent between groups or, as in the case of left ventricular ejection fraction, which was significantly lower in the unmatched complete ring cohort, actually favored improved freedom from recurrent $M R$ in the partial ring group. Despite this, partial ring recipients had higher rates of recurrence.

\section{Mechanistic Implications}

The primary structural difference between partial and complete rings is the ability of complete rings to maintain a fixed annular diameter as well as a fixed intertrigonal and septal-lateral distance regardless of ongoing geometric changes to other portions of the mitral valve apparatus. As such, the results of our study suggest that the higher rate of recurrent MR in the partial ring group is due, at least in part, to the overall effect that ongoing annular dilation of the anterior portion of the annulus (which is left unsupported in partial ring recipients) has in altering the overall geometry of the mitral apparatus. Classic teaching has been that only the posterior muscular portion of the mitral annulus dilates in FMR, but more recent work has demonstrated both 
in postmortem analysis of human beings with functional and myxomatous $\mathrm{MR}^{15}$ as well as in ovine models of $\mathrm{FMR}^{16}$ that the anterior fibrous portion of the mitral annulus also dilates. In addition, partial rings may be inferior in their ability to maintain a fixed septal-lateral distance, a measure that has been shown in experimental studies to be both necessary and sufficient to restore mitral competency. ${ }^{17,18}$ Although our study was not designed to measure changes in the length of the anterior portion of the annular circumference nor the intertrigonal and septal-lateral distances, our findings suggest that the anchoring effect of 1 trigone to the other as well as the relative stability of the septal-lateral distance inherent in the use of complete rings is likely the mechanism by which complete ring use imparts significant benefit to the durability of repair. Meanwhile, it should be noted that $10 \%$ of the unmatched cohort and $7 \%$ of matched cohort of complete ring recipients still developed MR recurrence during the study period, suggesting, in accordance with other studies, that factors other than ongoing anterior annular dilation such as displacement of the posterior papillary muscle ${ }^{19}$ and tethering of the posterior $^{20,21}$ or anterior ${ }^{22-24}$ leaflets, are likely to have been the mechanism for recurrence in patients in whom the annulus can be thought to have been more durably remodeled by the ring. Further studies are needed to test this hypothesis discretely.

\section{Survival}

Similar to other studies showing no affect on survival based on ring type, ${ }^{7,14}$ our study also demonstrated no survival difference between complete and partial ring recipients. True survival in the may actually be better in the complete ring group, but this effect may have been offset by the higher overall cardiovascular risk in this group, which may, in turn, be a result of a progressive institution-wide trend toward repairing MR in higher-risk patients. ${ }^{25}$ Another possibility is that the true difference in survival, if any, may be too small to detect given the number of patients in our study, in which case, the difference would essentially be clinically insignificant. Either way, it is clear there is no overwhelming survival benefit to using a complete ring demonstrated in this study. In addition, it is not possible to determine with currently available statistical methods whether or not recurrence is directly related to survival.

\section{Study Limitations}

In addition to the general limitations inherent in retrospective series, the primary limitation of our study was the reliance on postoperative echocardiograms to detect the occurrence of the primary end point. Routine predischarge echocardiograms are not performed universally at our institution, and are often only obtained in the setting of a specific clinical indication at the discretion of the surgeon and/or cardiologist. Therefore, there was wide variability in the time intervals for both the first and any subsequent postoperative echocardiograms. This may also account for the relatively late onset of MR recurrence in this study compared with other studies. In addition, echocardiograms were not re-reviewed to measure advanced echocardiographic measurements, including tenting height, tenting area, and tethering angles. Meanwhile, not only was there a significant difference in the overall echocardiographic follow-up interval between the unmatched groups, but also $12 \%$ of the original cohort of patients who met study criteria did not have any postoperative echocardiograms in our records at all. Although the influence of these 2 factors is difficult to predict, as noted above, a responder bias analysis showed no significant differences between these patients and those who did have postoperative echocardiographic data. In addition, Kaplan-Meier analysis has the ability to partially overcome this limitation, but our study still remains less conclusive than a similarly designed prospective trial.

Furthermore, as a nonrandomized study, there were significant differences in preoperative characteristics. As mentioned above, none of these differences favored improved outcomes in the complete ring group, and MR recurrence rates were higher in the partial ring group. We attempted to control for these differences using a risk-matched propensity model as well as Cox regression analysis, and found that the improved freedom from recurrent MR in the complete ring group retained significance in both of these analyses.

\section{Clinical Implications}

The observations in our study are in accordance with what many surgeons already believe anecdotally or have determined formally from their own clinical experience, ${ }^{12,26}$ and as such, several, but not all surgeons in our institution have shifted their practice from using partial rings to full rings for functional MR.

In the past, the primary argument in favor of the use partial rings included the suggestion that the risk of systolic anterior motion (SAM) is higher with complete rings ${ }^{27}$ due to anterior displacement of the leaflet coaptation point, secondary to excessive height or redundant tissue of the posterior leaflet. ${ }^{12}$ However, not only has this never been clearly demonstrated, the concern about SAM applies primarily in patients with myxomatous disease in whom, mechanistically speaking, the risk of SAM is higher, and not in patients with FMR in whom the leaflets are structurally normal and not redundant. Indeed, owing to the nonmyxomatous nature of our patient population, none of the patients in our study received a concomitant Alfieri stitch repair or any type of leaflet resection procedure. Given that the primary perceived disadvantage of using a complete ring is that of a higher theoretical risk of SAM, we believe that the improved freedom from recurrent MR demonstrated by our study forms 
a compelling argument in favor of the use of complete rings in all patients undergoing annuloplasty for FMR.

\section{CONCLUSIONS}

Compared to the use of partial rings, the use of complete rings for undersized mitral valve annuloplasty provides improved freedom from recurrent MR in patients undergoing mitral valve repair for FMR, but without any definite affect on patient survival.

\section{References}

1. Schmitto JD, Lee LS, Mokashi SA, Bolman RM 3rd, Cohn LH, Chen FY. Functional mitral regurgitation. Cardiol Rev. 2010;18:285-91.

2. Szeto WY, Gorman RC, Gorman JH III, Acker MA. ischemic mitral regurgitation. In: Cohn LH, ed. Cardiac surgery in the adult. New York: McGraw-Hill; 2008:785-802

3. Blondheim DS, Jacobs LE, Kotler MN, Costacurta GA, Parry WR. Dilated cardiomyopathy with mitral regurgitation: decreased survival despite a low frequency of left ventricular thrombus. Am Heart J. 1991;122(3 Pt 1):763-71.

4. Koelling TM, Aaronson KD, Cody RJ, Bach DS, Armstrong WF. Prognostic significance of mitral regurgitation and tricuspid regurgitation in patients with left ventricular systolic dysfunction. Am Heart J. 2002;144:524-9.

5. Robbins JD, Maniar PB, Cotts W, Parker MA, Bonow RO, Gheorghiade M. Prevalence and severity of mitral regurgitation in chronic systolic heart failure. Am J Cardiol. 2003;91:360-2.

6. Trichon BH, Felker GM, Shaw LK, Cabell CH, O'Connor CM. Relation of frequency and severity of mitral regurgitation to survival among patients with left ventricular systolic dysfunction and heart failure. Am J Cardiol. 2003;91:538-43.

7. McGee EC, Gillinov AM, Blackstone EH, Rajeswaran J, Cohen G, Najam F, et al. Recurrent mitral regurgitation after annuloplasty for functional ischemic mitral regurgitation. J Thorac Cardiovasc Surg. 2004;128:916-24.

8. Tahta SA, Oury JH, Maxwell JM, Hiro SP, Duran CM. Outcome after mitral valve repair for functional ischemic mitral regurgitation. $J$ Heart Valve Dis. 2002;11:11-8; discussion 18-9.

9. Hung J, Papakostas L, Tahta SA, Hardy BG, Bollen BA, Duran CM, et al. Mechanism of recurrent ischemic mitral regurgitation after annuloplasty: continued LV remodeling as a moving target. Circulation. 2004;110:1185-90.

10. Gillinov AM, Cosgrove DM. Mitral valve repair for degenerative disease. J Heart Valve Dis. 2002;11(Suppl 1):S15-20.

11. Chang BC, Youn YN, Ha JW, Lim SH, Hong YS, Chung N. Long-term clinical results of mitral valvuloplasty using flexible and rigid rings: a prospective and randomized study. J Thorac Cardiovasc Surg. 2007;133:995-1003.

12. Spiegelstein D, Moshkovitz Y, Sternik L, Fienberg MS, Kogan A, Malachy A, et al. Midterm results of mitral valve repair: closed versus open annuloplasty ring. Ann Thorac Surg. 2010;90:489-96.
13. Braun J, van de Veire NR, Klautz RJ, Versteegh MI, Holman ER, Westenberg JJ, et al. Restrictive mitral annuloplasty cures ischemic mitral regurgitation and heart failure. Ann Thorac Surg. 2008;85:430-6; discussion 436-7.

14. von Oppell UO, Stemmet F, Brink J, Commerford PJ, Heijke SA. Ischemic mitral valve repair surgery. J Heart Valve Dis. 2000;9:64-74.

15. Hueb AC, Jatene FB, Moreira LF, Pomerantzeff PM, Kallas E, de Oliveira SA. Ventricular remodeling and mitral valve modifications in dilated cardiomyopathy: new insights from anatomic study. J Thorac Cardiovasc Surg. 2002;124: 1216-24.

16. Gorman JH III, Gorman RC, Jackson BM, Enomoto Y, St John-Sutton MG, Edmunds LH Jr. Annuloplasty ring selection for chronic ischemic mitral regurgitation: lessons from the ovine model. Ann Thorac Surg. 2003;76:1556-63.

17. Tibayan FA, Rodriguez F, Langer F, Zasio MK, Bailey L, Liang D, et al. Annular or subvalvular approach to chronic ischemic mitral regurgitation? J Thorac Cardiovasc Surg. 2005;129:1266-75.

18. Miller DC. Ischemic mitral regurgitation redux-to repair or to replace? J Thorac Cardiovasc Surg. 2001;122:1059-62.

19. Vergnat M, Jassar AS, Jackson BM, Ryan LP, Eperjesi TJ, Pouch AM, et al. Ischemic mitral regurgitation: a quantitative three-dimensional echocardiographic analysis. Ann Thorac Surg. 2011;91:157-64.

20. Kuwahara E, Otsuji Y, Iguro Y, Ueno T, Zhu F, Mizukami N, et al. Mechanism of recurrent/persistent ischemic/functional mitral regurgitation in the chronic phase after surgical annuloplasty: importance of augmented posterior leaflet tethering. Circulation. 2006;114(Suppl.):I529-34.

21. Magne J, Pibarot P, Dagenais F, Hachicha Z, Dumesnil JG, Senechal M. Preoperative posterior leaflet angle accurately predicts outcome after restrictive mitral valve annuloplasty for ischemic mitral regurgitation. Circulation. 2007;115: 782-91.

22. van Garsse L, Gelsomino S, Lucà F, Lorusso R, Rao CM, Stefàno P, et al. Importance of anterior leaflet tethering in predicting recurrence of ischemic mitral regurgitation after restrictive annuloplasty. J Thorac Cardiovasc Surg. 2012;143(4 Suppl):S54-9.

23. Lee AP, Acker M, Kubo SH, Bolling SF, Park SW, Bruce CJ, et al. Mechanisms of recurrent functional mitral regurgitation after mitral valve repair in nonischemic dilated cardiomyopathy: importance of distal anterior leaflet tethering. Circulation. 2009;119:2606-14.

24. Ciarka A, Braun J, Delgado V, Versteegh M, Boersma E, Klautz R, et al. Predictors of mitral regurgitation recurrence in patients with heart failure undergoing mitral valve annuloplasty. Am J Cardiol. 2010;106:395-401.

25. Filsoufi F, Aklog L, Byrne JG, Cohn LH, Adams DH. Current results of combined coronary artery bypass grafting and mitral annuloplasty in patients with moderate ischemic mitral regurgitation. J Heart Valve Dis. 2004;13:747-53.

26. DiBardino DJ, ElBardissi AW, McClure RS, Razo-Vasquez OA, Kelly NE, Cohn LH. Four decades of experience with mitral valve repair: analysis of differential indications, technical evolution, and long-term outcome. J Throac Cardiovasc Surg. 2010;139:76-84.

27. Gillinov AM, Cosgrove DM 3rd, Shiota T, Qin J, Tsujino H, Stewart WJ, et al. Cosgrove-Edwards annuloplasty system: midterm results. Ann Thorac Surg. 2000;69:717-21. 